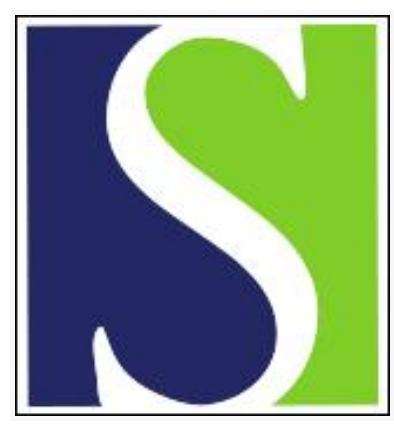

Scand J Work Environ Health 2009;35(3):193-202

https://doi.org/10.5271/sjweh.1325

Published online: 13 May 2009, Issue date: 00 May 2009

Sleep duration and sleep-related problems in different occupations in the Hordaland Health Study

by Ursin R, Baste V, Moen BE

Affiliation: Department of Biomedicine, University of Bergen, Jonas Lies vei 91, N-5009 Bergen, Norway. reidun.ursin@biomed.uib.no

Refers to the following texts of the Journal: 2008;34(3):198-205

2008;34(6):411-419 2006;32(6):493-501 1998;24(4):300-307

The following articles refer to this text: $2010 ; 36(2): 81-84$;

2010;36(6):515-516; 2017;43(3):260-268

Key terms: bedtime; Hordaland Health Study; insomnia; insufficient sleep; occupation; rise time; shift work; sleep duration; sleep-related problem; sleepiness

This article in PubMed: www.ncbi.nlm.nih.gov/pubmed/19436924

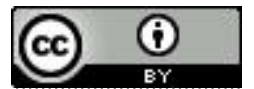




\title{
Sleep duration and sleep-related problems in different occupations in the Hordaland Health Study
}

by Reidun Ursin, MD, ${ }^{1,4}$ Valborg Baste, MSc, ${ }^{2}$ Bente E Moen, $P h D^{3}$

\begin{abstract}
Ursin R, Baste V, Moen BE. Sleep duration and sleep-related problems in different occupations in the Hordaland Health Study. Scand J Work Environ Health 2009;35(3):193-202.
\end{abstract}

\begin{abstract}
Objectives The aim of this study was to examine the relationship between occupation and sleep duration, sleepiness, insufficient sleep, and insomnia in day workers and shift workers (including night work and watches).

Methods The study was population-based and cross-sectional, and relied on self-administered questionnaires. It was conducted as part of the 1997-1999 Hordaland Health Study in collaboration with the Norwegian National Health Screening Service. Aged 40-45 years, 7782 participants answered a sleep questionnaire, reporting their occupation and whether or not they were employed in shift work.

Results Our study found differences in sleep duration during the working week between occupational groups; in both shift and day workers. Craft workers, plant operators, and drivers slept less than leaders, and non-personal and personal service workers. Within some occupations (leaders, personal service workers, and plant operators), shift workers slept less than day workers. The mean sleep duration of shift workers was 15 minutes shorter than that of day workers. Rise times, but not bedtimes, were earlier in craft-and construction workers, plant operators, and drivers than in leaders and non-personal and personal service workers, particularly day workers. When adjusted for shift work and working hours - compared to leaders - craft workers, plant operators, and drivers had an increased risk of daytime sleepiness (odds ratio 1.5, 1.8, and 1.8 respectively) and of falling asleep at work (odds ratio 1.6, 2.1 and 2.0 respectively). Shift workers had an increased risk of falling asleep at work and insomnia.
\end{abstract}

Conclusions Occupation has separate effects on sleep duration and sleep-related problems, independent of the effects of shift work.

Key terms insomnia; insufficient sleep; bedtime; rise time; shift work; sleepiness.

It is well known that disturbed sleep is common among shift workers (1-4), but there are few studies of sleep across different occupations. Occupational category has been reported to be a predictor of daytime sleepiness (3) and, in a large survey of 45-57 year olds, the frequency of insomnia was found to vary with occupation (5). In another large Finnish survey, main occupation was one of the determinants of short- and long-sleep duration (6).

Recently, the relationships between sleep, health, morbidity, and mortality have become important issues in medical research $(7,8)$. Differences in health and morbidity between occupational classes have been reported (9). Thus it is important to investigate whether there are variations in sleep duration and sleep problems between occupations, and whether these could be a factor for the development of health problems. Studies of sleep have so far neither looked simultaneously at the differences between groups of occupations and shift work nor have they tried to separate these effects.

In a previous population study of $40-45$ year olds, we found that shift workers and those on watch ("on guard" or "on call") had shorter sleep duration than day workers (10). In this study of the same population, we wanted to see whether sleep duration, sleepiness, insomnia, and other sleep-related problems vary with the type of occupation and if so, whether this is dependent on shift work.

1 Department of Biomedicine, University of Bergen, Bergen, Norway.

2 Occupational and Environmental Medicine, UNIFOB, Bergen, Norway.

3 Department of Public Health and Primary Health Care, University of Bergen, Bergen, Norway.

4 Norwegian Competence Center for Sleep Disorders, Haukeland University Hospital, Bergen, Norway.

Correspondence to: Dr Reidun Ursin, Department of Biomedicine, University of Bergen, Jonas Lies vei 91, N-5009 Bergen, Norway. [E-mail: reidun.ursin@biomed.uib.no] 


\section{Material and methods}

\section{Data collection}

The data collected for this study was part of the Hordaland Health Study. This cross-sectional study was conducted during 1997-1999 as a collaboration between the National Health Screening Service, the University of Bergen, and the local health services. Part of the project was funded by the Norwegian Ministry of Labour and Government Administration. The Hordaland study was restricted to the part of the population born 1953-1957. Thus, our study comprised all individuals in Hordaland county, born 1953-57 and aged 40-45 years old at the time of the data collection $(\mathrm{N}=29$ 400). Hordaland county (population 445000 ) is situated in the western part of southern Norway, at a latitude of $60^{\circ}$ north. Daylight varies from 19 hours in June to 6 hours in December. The county includes the city of Bergen which is the second largest city in Norway (population 250 000). The average levels of education and income in the county, and the average employment rate are close to those of the population of Norway (11).

A total of 8598 men and 9983 women participated in the Hordaland study, resulting in a participation rate of $63 \%$ ( $57 \%$ for men and $70 \%$ for women). The participants completed self-administered questionnaires with information on various health behaviors. A randomly selected $50 \%$ of the subjects who attended the health examination, were given a second questionnaire asking for detailed information on their sleep habits and problems.

The participation rate of those completing the questionnaire $(\mathrm{N}=8860)$ was $85 \%$ for men and $89 \%$ for women. The study protocol was approved by the Regional Ethics committee and the Norwegian data inspectorate.

\section{Variables}

Occupation for the last 12 months was classified for those who received income for at least 100 hours of the previous year and had written their occupation using free text (8010 subjects). The answers were coded by a person with special training and classified - using the International Standard Classification of Occupations (ISCO-88) (12) - into seven categories described in a previous paper (13): (i) leaders (legislators, senior officials and managers), (ii) professionals performing non-personal services (eg, science professionals, public administrators, business, and finance professionals), (iii) professionals performing services for other persons (eg, health personnel, teachers, and police), (iv) primary occupations (farmers, and forestry and fishery workers), (v) craft and related trade, and construction workers, and (vi) plant and machine operators (including assembly workers) and (vii) drivers (including mobile plant operators).

A total of 8343 subjects reported "yes" or "no" to a question on whether they had shift work (including night work) or watches (being "on call"), all grouped hereafter as shift work. The answers were not further qualified as to the content of the term or the frequency of morning, evening, or night shifts. Of these 8343 respondents, 7782 (3264 men and 4518 women) provided information on both their occupation and whether or not they were employed in shift work. The subjects were also asked to report the number of hours per week of paid work, and how many years experience they had in their present occupation. Table 1 shows the number of subjects in each occupational group, their gender and the percent which reported shift work.

The subjects completed a revised version of the Karolinska Sleep questionnaire $(10,14)$. We used the following variables in our study: (i) work week bed- and rise time, (ii) free time bed-and rise time, (iii) sleep latency on work week nights and free time nights, and (iv) subjective

Table 1. Classification and breakdown of occupational groups by gender and percentage of shift work (including night work and watches).

\begin{tabular}{|c|c|c|c|c|c|c|c|c|}
\hline \multirow[t]{2}{*}{ Occupational groups } & \multicolumn{3}{|c|}{ Men } & \multicolumn{3}{|c|}{ Women } & \multicolumn{2}{|c|}{ Total } \\
\hline & N & $\%$ & Shifts (\%) & $\mathrm{N}$ & $\%$ & Shifts (\%) & N & Shift $(\%)$ \\
\hline Leaders & 726 & 63.0 & 15.3 & 426 & 37.0 & 14.1 & 1152 & 14.8 \\
\hline Non-personal service workers & 727 & 41.9 & 15.4 & 1010 & 58.1 & 4.6 & 1737 & 9.1 \\
\hline Personal service workers & 707 & 20.1 & 29.8 & 2812 & 79.9 & 37.3 & 3519 & 35.8 \\
\hline Farmers, forestry \& fishery workers & 99 & 59.6 & 26.3 & 67 & 40.4 & 14.9 & 166 & 21.7 \\
\hline Craft \& construction workers & 601 & 88.4 & 24.1 & 79 & 11.6 & 8.9 & 680 & 22.4 \\
\hline Plant \& machine operators & 198 & 66.7 & 54.0 & 99 & 33.3 & 12.1 & 297 & 40.1 \\
\hline Drivers & 206 & 89.2 & 63.6 & 25 & 10.8 & 68.0 & 231 & 64.1 \\
\hline Total material & 3264 & 41.9 & 25.8 & 4518 & 58.1 & 26.6 & 7782 & 26.3 \\
\hline
\end{tabular}


sleep need. The duration of a "normal" night's sleep in a work week and during free time was calculated as "rise time minus bedtime minus the individual's sleep latency" (10). Questions on tiredness or sleepiness at work or during free time, insufficient sleep (at least one hour less than the subjective sleep need), and falling asleep at work were answered on a 5 point scale ("never", "a few times a year", "a few times a month", "several times a week", "always"). Participants also answered a question on their preference for mornings versus evenings using a five point scale ("pronounced morningness", "more morning- than eveningness", "neither", "more eveningthan morningness", "pronounced eveningness"). They answered a question on insomnia (10) using a four point scale ("never or a few times a year", "1-2 times per month", "about once per week", "more than once per week"). The subjects also answered a question on subjective health ("how is your health now?") on a fourpoint scale ("very good", "good", "not quite good" and "poor").

Information was collected on (i) working hours per week, (ii) sedentary or manual work situation, (iii) education, (iv) family income, (iv) marital status, (v) urban versus rural living, and (vi) amount of exercise taken, smoking and alcohol consumption. Data was collected throughout the year with the exception of July. The time of year or month in which the data were collected did not result in any significant differences in the study population's sleep duration or subjective sleep need (10).

\section{Statistics}

Univariate analyses of variance were performed to test differences in the mean duration of normal sleep during the work week and free time and differences in the subjective sleep need, between occupational groups and between shift workers and day workers. The model included occupational groups, shift work, gender and working hours. The main effects and interactions between occupational group and shift work were tested. In addition, we tested the mean work week sleep durations in the different occupations separately for shift workers and day workers with analyses of variance, adjusting for gender and working hours. Similar analyses were done for each gender separately. Unadjusted analyses of variance were used to compare sleep duration in shift workers versus day workers.

We also used univariate analyses of variance to compare groups, with bed- or rise time as dependent variables, and shift work and occupational group as fixed factors, testing for main effects and interactions, and adjusting for gender and working hours. Data from 50 night workers who had bedtimes of 05.00 or later were not included in the bed-and rise time calculations (10).
In all cases, we used post hoc Bonferroni for multiple testing on differences between occupational groups.

Sleep-related problems were dichotomized as follows: sleepiness and insufficient sleep: "never/ a few times a year, a few times a month" versus "several times a week/always"; falling asleep at work: "never/a few times a year" versus "a few times a month/several times a week/always"; insomnia: "never or a few times a year/1-2 times per month" versus "about once per week/more than once per week" (10).

We applied logistic regression analyses to evaluate the influence of occupation and shift work on the four sleep-related problems. In an initial step, occupational group, shift work, gender, working hours (continuous variable), and an interaction between occupational group and shift work were analyzed. There was no significant interaction between occupation and shift work for any of the sleep-related problems, so in a second step the analyses were run without the interaction term. The effects were estimated as odds ratio (OR) with $95 \%$ confidence intervals $(95 \% \mathrm{CI})$. We used "leader" as the reference category within occupation. For shift work, "day workers" was used as the reference; "men" was the reference category for gender.

The estimated effects were also adjusted for socioeconomic and health factors (education, family income, marriage status, urban/rural living, subjective health, smoking, and alcohol use) in a logistic regression. It was not possible to conduct separate analyses of shift work and day work since the response rates for the questions on sleep-related problems were too low to draw adequate conclusions.

Data on sleep duration and subjective sleep need are denoted in decimal hours, while bed- and rise time data are given in clock time (except in figure 1 where decimal clock time is used). The data were analyzed with Statistical Package for the Social Sciences version 11.5 (SPSS Inc, Chicago, IL, USA) and significance level was set to $\mathrm{P}<0.05$.

\section{Results}

\section{Working hours and work experience}

The mean working hours per week for men was 39.0 hours [95\% CI 38.7-39.4; standard deviation (SD) 9.8] and 30.0 hours for women ( $95 \%$ CI $29.7-30.4$; SD 1.4). The mean working hours per week for male shift workers was 41.0 hours (95\% CI 40.2-41.8; SD 11.7); for women it was 30.0 hours (95\% CI 29.5-30.6; SD 10.2). For male day workers, the mean working hours per week was 38.3 hours (95\% CI 38.0-38.6, SD 8.7) and for women it was 30.2 hours (95\% CI 29.9-30.6; SD 11.6). 
Three percent of the participants reported zero work hours, while $1.7 \%$ of participants reported working less than 10 hours per week; the majority (89.4\%) reported working more than 20 hours per week, including 2.6\% who reported working more than 50 hours per week. The participants had a mean of 14 years experience in their current occupation (95\% CI 14.0-14.4, SD 7.5).

\section{Sleep duration}

Normal sleep duration during a work week is set out in table 2. The duration of sleep in the total material during the work week differed among occupational groups $(\mathrm{P}<0.001)$ and between shift workers and day workers $(\mathrm{P}<0.001)$, and between genders $(\mathrm{P}<0.001)$, adjusting for work hours. Craft and construction workers, plant operators, and drivers had significantly shorter sleep duration than leaders, those in service occupations, and farmers and fishery workers. Shift workers slept significantly shorter hours than day workers. Women had significantly longer sleep duration than men in all occupational groups with the exception of plant operators and drivers (data not shown; 0.4 hours longer for leaders, farmers and fishery workers, and craft and construction workers; and 0.2 hours longer for nonpersonal and personal service workers).

The duration of normal night sleep during free time was more than 1 hour longer than during the work week in all occupations (table 2). Sleep duration during free time did not vary among occupations $(\mathrm{P}=0.256)$ and there was no effect of shift work $(\mathrm{P}=0.687)$. There was a gender effect $(\mathrm{P}<0.001)$ as demonstrated earlier $(10)$.

There were significant interactions between occupational groups and shift working, occupational groups and gender, and shift working and gender, adjusting for working hours (all $\mathrm{P}<0.001$ ). Table 2 shows that the mean duration of shift workers' normal night sleep was around 15 minutes ( 0.25 hours) shorter than that of day workers $(\mathrm{P}<0.001)$. The duration of sleep in shift and day workers for men and women has been reported earlier (10). Adjusted for gender and working hours, there were significant effects of occupational group on sleep duration both for shift and day workers $(\mathrm{P}=0.015$ and $\mathrm{P}<0.001$, respectively).

In shift workers, (i) craft and construction workers had a shorter sleep duration than personal service workers $(\mathrm{P}<0.05)$, (ii) plant operators had shorter sleep duration than leaders $(\mathrm{P}<0.05)$, and non-personal $(\mathrm{P}<0.01)$ and personal $(\mathrm{P}<0.001)$ service workers, and (iii) drivers had shorter sleep duration than the nonpersonal and personal service workers $(\mathrm{P}<0.01$ and $\mathrm{P}<0.001$, respectively).

In day workers, craft and construction workers, plant operators, and drivers all had shorter sleep duration than leaders, those in service occupations, and farmers and fishery workers $(\mathrm{P}<0.001)$ as highlighted in table 2 .

Table 2. Work week and free time normal night sleep duration, and subjective sleep need (mean hours), in the total material, in subjects with shift work (including night work and watches) and day work and in the occupational groups. Not all subjects responded to all questions presented here. $(95 \% \mathrm{Cl}=95 \%$ confidence interval)

\begin{tabular}{|c|c|c|c|c|c|c|c|c|c|c|c|}
\hline & \multirow[t]{3}{*}{ N } & \multicolumn{6}{|c|}{ Work week normal night sleep duration } & \multirow{2}{*}{\multicolumn{2}{|c|}{$\begin{array}{c}\text { Free time } \\
\text { normal night } \\
\text { sleep duration }\end{array}$}} & \multirow{2}{*}{\multicolumn{2}{|c|}{$\begin{array}{l}\text { Subjective } \\
\text { sleep need }\end{array}$}} \\
\hline & & \multicolumn{2}{|c|}{ Total material } & \multicolumn{2}{|c|}{ Shift work } & \multicolumn{2}{|c|}{ Day work } & & & & \\
\hline & & Mean & $95 \% \mathrm{Cl}$ & Mean & $95 \% \mathrm{Cl}$ & Mean & $95 \% \mathrm{Cl}$ & Mean & $95 \% \mathrm{Cl}$ & Mean & $95 \% \mathrm{Cl}$ \\
\hline \multicolumn{12}{|l|}{ Occupational groups } \\
\hline Leaders & 1152 & 7.07 & $7.02-7.12$ & $6.84^{a}$ & $6.65-7.03$ & 7.10 & $7.05-7.15$ & 8.17 & $8.11-8.23$ & 7.55 & $7.53-7.57$ \\
\hline Non-personal service workers & 1737 & 7.04 & $7.00-7.09$ & 6.92 & $6.72-7.12$ & 7.05 & $7.02-7.09$ & 8.23 & $8.18-8.28$ & 7.38 & $7.33-7.43$ \\
\hline Personal service workers & 3519 & 7.12 & $7.09-7.16$ & $6.94^{\mathrm{a}}$ & $6.87-7.01$ & 7.21 & $7.17-7.25$ & 8.26 & $8.22-8.29$ & 7.53 & $7.49-7.57$ \\
\hline Farmers \& fishery workers & 166 & 7.18 & $7.05-7.32$ & 7.06 & $6.79-7.32$ & 7.22 & $7.06-7.39$ & 7.91 & $7.75-8.07$ & 7.66 & $7.63-7.69$ \\
\hline Craft \& construction workers & 680 & $6.74^{b}$ & $6.67-6.81$ & $6.62^{c}$ & $6.45-6.79$ & $6.78^{\mathrm{b}}$ & $6.70-6.85$ & 8.05 & $7.96-8.14$ & 7.58 & $7.44-7.73$ \\
\hline Plant \& machine operators & 297 & $6.62^{b}$ & $6.48-6.76$ & $6.38^{d, e, t}$ & $6.14-6.62$ & $6.72^{b}$ & $6.56-6.89$ & 8.13 & $8.00-8.27$ & 7.29 & $7.22-7.36$ \\
\hline Drivers & 231 & $6.55^{b}$ & $6.39-6.70$ & $6.48^{e}$ & $6.28-6.68$ & $6.64^{b}$ & $6.42-6.87$ & 8.20 & $8.04-8.36$ & 7.33 & $7.21-7.44$ \\
\hline \multicolumn{12}{|l|}{ Shift work/watches } \\
\hline Shift work & 2044 & $6.85^{g}$ & $6.80-6.90$ & . & .. & . & .. & 8.19 & $8.14-8.25$ & 7.54 & $7.50-7.59$ \\
\hline Day work & 5738 & 7.10 & $7.08-7.13$ & . & .. & . & .. & 8.20 & $8.17-8.23$ & 7.54 & $7.52-7.56$ \\
\hline Total material & 7782 & 7.05 & $7.03-7.08$ & $6.85^{g}$ & $6.80-6.90$ & 7.10 & $7.08-7.13$ & 8.19 & $8.17-8.22$ & 7.55 & $7.53-7.57$ \\
\hline
\end{tabular}

a Significantly different from day workers, same occupational group, $\mathrm{P}=0.001$.

b Significantly different from leaders, non-personal and personal service workers, and farmers, $\mathrm{P}<0.001$.

c Significantly different from personal service workers $\mathrm{P}<0.05$.

d Significantly different from leaders $\mathrm{P}<0.05$.

e Significantly different from non-personal and personal service workers, $P<0.01$ and $P<0.001$ respectively.

${ }^{+}$Significantly different from day workers, same occupational group, $P<0.05$.

${ }^{g}$ Significantly different from day workers $\mathrm{P}<0.001$. 
Within the same occupational group, there were differences in sleep duration between shift and day workers for leaders $(\mathrm{P}=0.05)$, personal service workers $(\mathrm{P}<0.001)$, and plant operators $(\mathrm{P}=0.05)$. Adjusting for gender and working hours, we found that shift workers have shorter sleep duration. For non-personal service workers and craft workers, the differences were not significant (both $0.05<\mathrm{P}<0.10$ ).

We also ran univariate analyses of variance separately for men and women, adjusting for working hours. Among men, occupation had a significant effect on sleep duration in day workers but not shift workers $(\mathrm{P}<0.001$ and $\mathrm{P}=0.056$, respectively). We found a similar effect of occupation in women $(\mathrm{P}<0.001$ for day workers and $\mathrm{P}=0.213$ for shift workers).

Table 3 shows the number of workers in the different occupational groups who had $<6$ hours of sleep at night during the working week. Adjusting for gender and working hours, we found no effect of occupation on the sleep durations $(\mathrm{P}=0.372)$ but an effect of shift work $(\mathrm{P}<0.001$; data not shown). However, it is evident from the table that the percentage of workers reporting such very short sleep at night differs among occupational groups, both in shift and day workers, with craft workers, plant operators, and drivers having the highest percentage of all occupational groups.

\section{Subjective sleep need}

Participants reported a subjective sleep need that was around 0.5 hours longer than work week sleep duration, and 0.5 hours shorter than the duration of sleep during free time (table 2). Adjusting for working hours, we found no effect of either occupational group $(\mathrm{P}=0.124)$

Table 3. Number and percent in each occupational group reporting less than 6 hours of sleep during a normal work week night, in total and among day workers and shift workers (including night work and watches).

\begin{tabular}{|c|c|c|c|c|c|c|}
\hline \multirow[t]{3}{*}{ Occupational groups } & \multicolumn{6}{|c|}{ Sleeping $<6$ hours } \\
\hline & \multicolumn{2}{|c|}{ Shift workers } & \multicolumn{2}{|c|}{ Day workers } & \multicolumn{2}{|c|}{ Total } \\
\hline & $\mathrm{N}$ & $\%^{a}$ & $\mathrm{~N}$ & $\%^{\mathrm{b}}$ & $\mathrm{N}$ & $\% c$ \\
\hline Leaders & 30 & 17.5 & 53 & 5.4 & 88 & 7.6 \\
\hline Non-personal service workers & rs 27 & 17.1 & 110 & 7.0 & 140 & 8.1 \\
\hline Personal service workers & 162 & 12.9 & 141 & 6.2 & 310 & 8.8 \\
\hline Farmers \& fishery workers & 1 & 2.8 & 6 & 4.6 & 8 & 4.8 \\
\hline Craft \& construction workers & s 28 & 18.4 & 72 & 13.6 & 102 & 15.0 \\
\hline Plant \& machine operators & 25 & 21.0 & 26 & 14.6 & 51 & 17.2 \\
\hline Drivers & 42 & 28.4 & 15 & 18.1 & 57 & 24.7 \\
\hline
\end{tabular}

a Percentage of occupational group among shift workers.

${ }^{b}$ Percentage of occupational group among day workers.

c Percentage of occupational group. or shift work ( $\mathrm{P}=0.997)$, but we did find an effect of gender $(\mathrm{P}<0.001)$. Women reported a higher subjective sleep need than men as demonstrated earlier (10).

\section{Bed- and rise time during the work week}

Excluding night workers, figure 1 shows the normal bedtimes of shift workers and day workers during the working week for the different occupational groups.

Overall, after adjusting for gender and working hours, we found an effect of occupation $(\mathrm{P}<0.001)$ on bedtimes, but no effect of shift work $(\mathrm{P}=0.576)$. The mean bedtime for shift workers (night workers excluded) during the work week was (clock time) 23.07 hours (95\% CI 3.0523.09 ) and 23.08 hours (95\% CI 23.07-23.10) for day workers. There was an interaction between occupation and shift work $(\mathrm{P}<0.001)$. This was probably because

\section{BEDTIME}

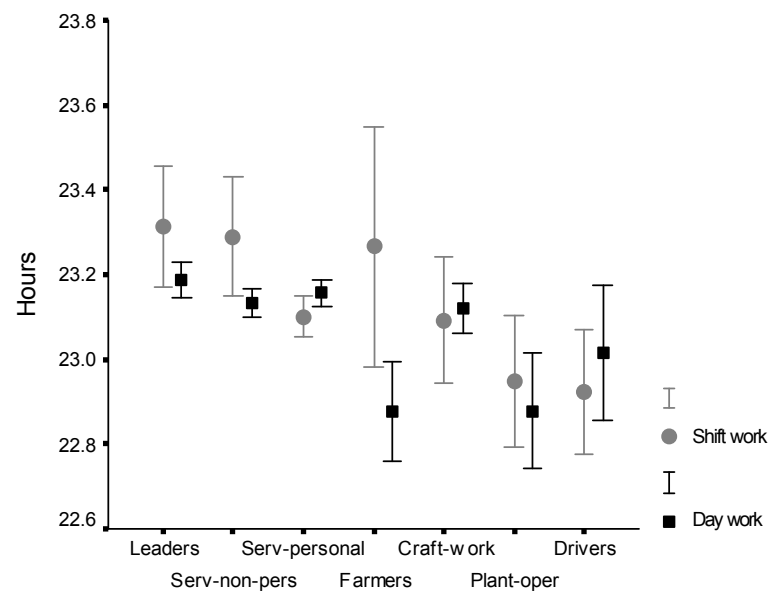

RISE TIME

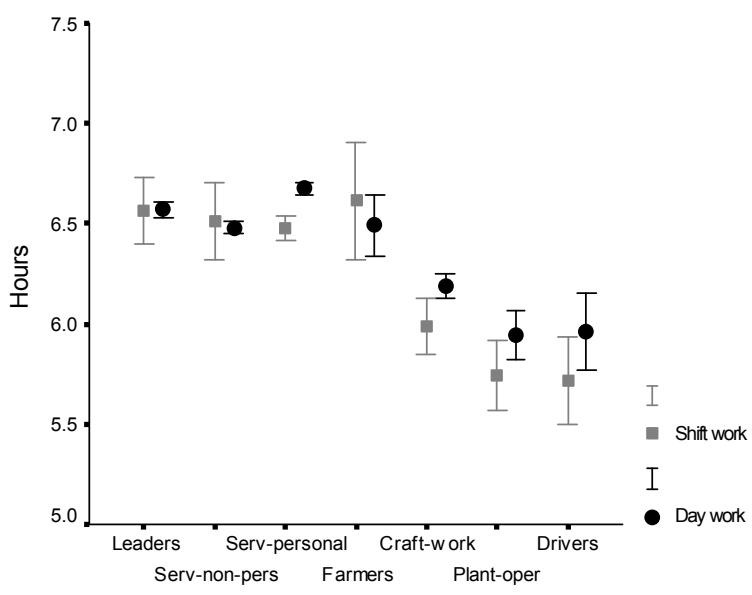

Figure 1. Mean bed- and rise time during the work week (decimal clock time with $95 \%$ confidence interval) in the different occupational groups, and for day and shift workers (night workers not included). 
subjects in some occupational groups who reported shift work (leaders, non-personal service workers, and particularly farmers and fishery workers) had later bedtimes than those who did not report shift work; there were less differences for the other occupational groups.

In the total material, we found an effect on rise time of occupational group $(\mathrm{P}<0.001)$ and shift work $(\mathrm{P}<0.001)$, and an interaction between occupational group and shift work $(\mathrm{P}<0.001)$, adjusting for gender and working hours. Normal rise times for those who reported shift work or day work are given in figure 1. There was an effect of occupational group in both shift workers and day workers $(\mathrm{P}<0.001)$.

In shift workers, post hoc tests indicated significant differences between leaders and the non-personal and personal services, and farmers and fishery workers, on the one hand, and craft and construction workers, plant operators and drivers on the other hand (all $\mathrm{P}<0.001)$. Differences were also noted between farmers, fishery workers and plant operators $(\mathrm{P}<0.01)$ and drivers $(\mathrm{P}<0.001)$.

In day workers, there were significant differences between (i) leaders and the non-personal service workers $(\mathrm{P}<0.05)$, (ii) leaders and the personal service workers $(\mathrm{P}<0.01)$, and (iii) leaders, non-personal and personal service workers and farmers and fishery workers, on the one hand, and craft and construction workers, plant operators, and drivers on the other hand (all $\mathrm{P}<0.001$ ), and (iv) between craft- and construction workers and plant operators $(\mathrm{P}<0.001)$.

\section{Bed- and rise time during free time}

Adjusting for gender and working hours, we found differences in bedtimes during free time among occupational groups $(\mathrm{P}<0.001)$ and shift workers $(\mathrm{P}<0.01)$, and an interaction between occupation and shift work $(\mathrm{P}<0.001)$. The normal bedtime of shift workers during free time was (clock time) 23.57 hours (95\% CI 23.54-23.59); for day workers, it was 0.03 hours $(95 \%$ CI $0.02-0.04)$. There were no significant differences between occupations. In day workers, farmers and fishery workers had earlier bedtimes (23.57 hours; 95\% CI 23.18-23.36) than all other occupational groups $(\mathrm{P}<0.01-0.001)$. The bedtimes of other occupational groups did not differ significantly from each other [leaders 0.06 hours (95\% CI 0.03-0.09), and drivers 0.01 hours (95\% CI 23.50-0.13)].

Occupational group had an effect $(\mathrm{P}<0.001)$ on rise time during free time; we found no effect of shift work ( $\mathrm{P}=0.329)$, but an interaction between occupation and shift work $(\mathrm{P}<0.001)$. The rise time of shift workers was 08.30 hours (95\% CI 8.27-8.33); for day workers it was 08.33 hours (95\% CI 8.31-8.35). Among shift workers, farmers and fishery workers had earlier rise times than leaders $(\mathrm{P}<0.01)$, non-personal service workers $(\mathrm{P}<0.05)$, and personal service workers $(\mathrm{P}<0.01)$. Among day workers, farmers and fishery workers rose 30-40 minutes earlier than all the other occupational groups (all $\mathrm{P}<0.001$ ). Plant operator shift workers had earlier rise times than day workers: 8.17 hours $(95 \%$ CI $8.03-8.32)$ versus 8.33 hours (95\% CI 8.23-8.44).

\section{Morningness versus eveningness}

Adjusting for gender and shift work, we found differences $(\mathrm{P}<0.01)$ between occupational groups as to whether subjects characterized themselves as being a morning versus evening person ("morningness" versus "eveningness"). Leaders and service workers tended to have a preference for evenings; there was no difference

Table 4. Prevalence (\%) of complaints of daytime sleepiness, insufficient sleep, falling asleep at work and insomnia in the total material, in subjects with shift work (including night work and watches) and day work and among occupational groups.

\begin{tabular}{|c|c|c|c|c|c|c|c|c|}
\hline \multirow[t]{2}{*}{ Overall prevalence } & \multicolumn{2}{|c|}{$\begin{array}{c}\text { Daytime sleepiness }{ }^{\mathrm{a}} \text {, } \\
13.5\end{array}$} & \multicolumn{2}{|c|}{$\begin{array}{l}\text { Insufficient sleep a } \\
20.6\end{array}$} & \multicolumn{2}{|c|}{$\begin{array}{l}\text { Falling asleep at work }{ }^{\mathrm{b}} \\
5.5\end{array}$} & \multicolumn{2}{|c|}{$\begin{array}{l}\text { Insomnia c } \\
11.4\end{array}$} \\
\hline & Shiftwork & $\begin{array}{l}\text { Day } \\
\text { work }\end{array}$ & Shiftwork & $\begin{array}{l}\text { Day } \\
\text { work }\end{array}$ & Shiftwork & $\begin{array}{l}\text { Day } \\
\text { work }\end{array}$ & Shiftwork & $\begin{array}{l}\text { Day } \\
\text { work }\end{array}$ \\
\hline \multicolumn{9}{|l|}{ Occupational groups } \\
\hline Leaders & 13.0 & 8.9 & 21.0 & 17.3 & 9.4 & 4.4 & 14.1 & 8.0 \\
\hline Non-personal service workers & 14.4 & 13.4 & 19.9 & 20.4 & 7.7 & 4.9 & 10.3 & 9.3 \\
\hline Personal service workers & 13.3 & 12.1 & 20.2 & 20.5 & 4.4 & 3.4 & 12.6 & 9.9 \\
\hline Farmers \& fishery workers & 18.8 & 13.6 & 21.2 & 22.2 & 10.0 & 7.1 & .. & 9.2 \\
\hline Craft \& construction workers & 13.6 & 12.4 & 18.2 & 20.4 & 14.6 & 8.2 & 12.1 & 9.1 \\
\hline Plant \& machine operators & 12.9 & 18.9 & 22.2 & 20.6 & 18.6 & 7.5 & 14.6 & 9.1 \\
\hline Drivers & 16.4 & 12.9 & 27.1 & 17.1 & 16.0 & 8.8 & 15.0 & 8.8 \\
\hline All occupations & 13.7 & 12.9 & 20.8 & 20.2 & 7.4 & 4.8 & 12.8 & 9.9 \\
\hline
\end{tabular}

a Several times a week to always.

${ }^{b}$ A few times per month to always.

c $\geq 1$ times per week. 
Table 5. Mutually adjusted odds ratios (OR) and 95\% confidence intervals $(95 \% \mathrm{Cl})$ for reporting daytime sleepiness, insufficient sleep, falling asleep at work, and insomnia, in different occupational groups. Statistically significant odds ratios $(\mathrm{P}<0.05)$ appear in boldface.

\begin{tabular}{|c|c|c|c|c|c|c|c|c|c|c|c|c|c|c|c|c|}
\hline \multirow[t]{3}{*}{ Occupational groups } & \multicolumn{8}{|c|}{ Model ${ }^{\mathrm{a}}$} & \multicolumn{8}{|c|}{ Adjusted $^{b}$} \\
\hline & \multicolumn{2}{|c|}{$\begin{array}{l}\text { Daytime } \\
\text { sleepiness }\end{array}$} & \multicolumn{2}{|c|}{$\begin{array}{l}\text { Insufficient } \\
\text { sleep }\end{array}$} & \multicolumn{2}{|c|}{$\begin{array}{l}\text { Falling asleep } \\
\text { at work }\end{array}$} & \multicolumn{2}{|c|}{ Insomnia } & \multicolumn{2}{|c|}{$\begin{array}{l}\text { Daytime } \\
\text { sleepiness }\end{array}$} & \multicolumn{2}{|c|}{$\begin{array}{l}\text { Insufficient } \\
\text { sleep }\end{array}$} & \multicolumn{2}{|c|}{$\begin{array}{l}\text { Falling asleep } \\
\text { at work }\end{array}$} & \multicolumn{2}{|c|}{ Insomnia } \\
\hline & $\mathrm{OR}$ & $95 \% \mathrm{Cl}$ & $\mathrm{OR}$ & $95 \% \mathrm{Cl}$ & $\mathrm{OR}$ & $95 \% \mathrm{Cl}$ & OR & $95 \% \mathrm{Cl}$ & $\mathrm{OR}$ & $95 \% \mathrm{Cl}$ & $\mathrm{OR}$ & $95 \% \mathrm{Cl}$ & OR & $95 \% \mathrm{Cl}$ & $\mathrm{OR}$ & $95 \% \mathrm{Cl}$ \\
\hline Leaders (reference) & 1.0 & . & 1.0 & . & 1.0 & . & 1.0 & . & 1.0 & . & 1.0 & . & 1.0 & . & 1.0 & . \\
\hline $\begin{array}{l}\text { Non-personal service } \\
\text { workers }\end{array}$ & 1.4 & $1.1-1.8$ & 1.1 & $0.9-1.4$ & 1.2 & $0.8-1.7$ & 1.0 & $0.7-1.3$ & 1.2 & 0.9 & 1.1 & $0.9-1.4$ & 1.1 & $0.8-1.7$ & 0.8 & $0.6-1.1$ \\
\hline $\begin{array}{l}\text { Personal service workers } \\
\text { Farmers \& fishery }\end{array}$ & 1.1 & $0.9-1.4$ & 1.1 & $0.9-1.3$ & 0.9 & $0.6-1.2$ & 1.0 & $0.8-1.3$ & 1.1 & $0.9-1.5$ & 1.1 & $0.9-1.3$ & 0.9 & $0.6-1.3$ & 0.8 & $0.6-1.1$ \\
\hline $\begin{array}{l}\text { workers } \\
\text { Craft \& construction }\end{array}$ & 1.7 & $1.0-3.0$ & 1.3 & $0.8-2.0$ & 1.4 & $0.7-3.1$ & 0.8 & $0.4-1.6$ & 1.7 & $0.8-3.5$ & 1.1 & $0.6-2.1$ & 1.3 & $0.5-4.0$ & 0.3 & $0.1-1.0$ \\
\hline $\begin{array}{l}\text { workers } \\
\text { Plant \& machine }\end{array}$ & 1.5 & $1.1-2.0$ & 1.2 & $0.9-1.6$ & 1.6 & $1.1-2.4$ & 1.2 & $0.8-1.6$ & 1.2 & $0.8-1.9$ & 1.2 & $0.9-1.7$ & 1.8 & $1.1-3.0$ & 0.7 & $0.5-1.1$ \\
\hline operator & 1.8 & $1.2-2.6$ & 1.2 & $0.9-1.7$ & 2.1 & $1.3-3.4$ & 1.2 & $0.8-1.8$ & 2.0 & $1.2-3.3$ & 1.5 & $1.0-2.3$ & 2.6 & $1.4-4.8$ & 0.9 & $0.5-1.5$ \\
\hline Drivers & 1.8 & $1.2-2.8$ & 1.5 & $1.0-2.2$ & 2.0 & $1.2-3.3$ & 1.3 & $0.8-2.2$ & 1.4 & $0.8-2.5$ & 1.7 & $1.1-2.7$ & 2.0 & $1.1-3.8$ & 0.9 & $0.5-1.6$ \\
\hline $\begin{array}{l}\text { Shift worker } \\
\text { (reference day workers) }\end{array}$ & 1.2 & $1.0-1.4$ & 1.0 & $0.9-1.2$ & 1.6 & $1.3-2.0$ & 1.4 & $1.2-1.6$ & 1.1 & $1.0-1.3$ & 1.0 & $0.9-1.2$ & 1.5 & $1.1-2.0$ & 1.3 & $1.0-1.6$ \\
\hline Gender (reference men) & 1.3 & $1.1-1.5$ & 1.2 & $1.1-1.4$ & 0.5 & $0.4-0.6$ & 1.2 & $1.0-1.6$ & 1.5 & $1.2-1.8$ & 1.4 & $1.2-1.6$ & 0.6 & $0.4-0.8$ & 1.3 & $1.0-1.5$ \\
\hline
\end{tabular}

a Model includes occupational group, shift work, gender, and working hours. Work hours: OR 1.0 for all sleep problems tested.

${ }^{\mathrm{b}}$ Adjusted for work situation (4 categories), education (continuous, 6 levels) family income (continuous, 9 levels), marriage status (2 categories), urban/rural living (2 categories), subjective health (4 categories), exercise (continuous), smoking (2 categories), and alcohol use (continuous).

in craft workers and plant operators, while drivers tended to have a preference for mornings. Post hoc tests indicated a significant difference between drivers and personal service workers, but found no other significant differences between occupational groups (data not shown).

\section{Sleep-related problems}

Table 4 shows the prevalence of sleepiness during the day, insufficient sleep, falling asleep at work, and insomnia in shift workers and day workers, and across the different occupations. Table 5 shows the odds ratios for sleep-related problems, comparing (i) all occupations to the reference group of leader, (ii) shift workers to day workers, and (iii) women to men. Working hours were also included in the model as a continuous variable but had little influence on the odds ratios for any of the sleep problems.

In the crude analysis, compared to leaders, non-personal service workers, farmers and fishery workers, craft and construction workers, plant and machine operators, and drivers, all had increased risk of sleepiness complaints (table 5). Craft and construction workers, plant and machine operators, and drivers had increased risk of falling asleep at work compared to leaders. Compared to day workers, shift workers had increased risk of falling asleep at work and insomnia.

When adjusting for sedentary/manual work situation, and socioeconomic and health factors, there were some reductions in the odds ratios for sleepiness, but the risk factors for falling asleep at work and insomnia were unchanged (table 5).

\section{Discussion}

Our study demonstrates that occupational group as well as shift work have clear effects on several sleep parameters. The sleep parameters varied between occupations, both in shift and day workers. In fact, this was particularly clear among day workers, where normal sleep duration during the working week was shorter in craft and construction workers, plant and machine operators, and drivers on the one hand, than in leaders, those in service occupations and farmers and fishery workers on the other hand. The shorter sleep duration of craft and construction workers, plant and machine operators, and drivers was accompanied by earlier rise times in these occupational groups. As demonstrated in this population in a previous study (10), sleep duration during the work week was shorter for shift workers than day workers. Workers in non-personal services, farmers and fishery workers, craft and construction workers, plant and machine operators, and drivers, all had an increased risk of sleepiness during the day compared to leaders. Moreover, compared to leaders, drivers had an increased risk of reporting insufficient sleep, while craft and construction workers, plant and machine operators, and drivers had an increased risk of falling asleep at work. Shift workers had an increased 
risk of falling asleep at work and insomnia complaints. There were no occupation-related differences in the risk for insomnia.

There are few studies on sleep across occupations. In a study of subjective health complaints in 602 subjects, there were no significant differences in self-reported sleep quantity or quality among five occupational groups (15). Occupational category was a predictor of daytime sleepiness in a Finnish study (3), with subjects working in transport and traffic complaining less about daytime sleepiness than clerical workers, factory workers, and machine operators. In the present study, craft and construction workers, plant and machine operators, and drivers (all manual workers) had a shorter sleep duration, and higher risk of daytime sleepiness or insufficient sleep complaints and falling asleep at work, than leaders and personal service workers, who are mostly non-manual workers.

The sleep of drivers in particular has been extensively studied (16-18). The mean work week sleep duration of the drivers in our study was 6.55 hours, almost 2 hours longer than the 4.78 hours reported by Mitler et al (16), and slightly more than the 6.28 hours sleep reported by Hanowski et al (18) for drivers following the 2003 US regulations on hours of service. Nevertheless, the drivers in our study had an increased risk of daytime sleepiness compared to leaders; they reported insufficient sleep, and had double the risk compared to leaders of falling asleep at work.

Insomnia complaints varied between 40 different occupational groups in a large Finnish survey (5). In our study, reports on insomnia did not differ between the seven occupational groups, but was a characteristic of those doing shift work.

In this study, mean sleep duration during the work week in all occupational groups was close to the sleep durations (6.5-7.5 hours) reported by Kripke et al (19) as having the lowest mortality risk. However, sleep durations of $<6$ hours were reported by some workers in all occupational groups. Craft-and construction workers, plant operators, and drivers reported frequent daytime sleepiness or insufficient sleep. Insufficient sleep may affect performance (20), traffic safety (21), and quality of life in general (22). In addition, insufficient sleep is a risk factor for cardiovascular disease (8) and diabetes mellitus $(7,23)$. Short sleep duration has been associated with elevated body mass index and obesity $(24,25)$. Further research is necessary to see whether the sleep differences between occupations found in this study may be risk factors for such health issues. In a recent Swedish study, there were minor effects on risks for sleep apnea of socioeconomic status and occupation, particularly in men (26). Differences in health and morbidity between occupational classes in men have been reported in a study of seven European countries (9). Morbidity higher than the population average was described for skilled and unskilled manual workers. Our data extended the difference in health factors between manual and non-manual workers to sleep and sleep-related factors.

The relationship between occupational groups and sleep duration needs further investigation in order to be understood. Socioeconomic factors had a very low impact on sleep in this material (10). However, working conditions within the different occupational groups might be of importance. We know that psychosocial stress in general may impair sleep (27) and this stress may be present at the workplace. The stress situation can be mental, as when an imbalance in effort-reward is present (28), or related to physical stressors like heavy lifting (29). Also, individual factors, such as leisure time activities and circadian factors, may be of relevance to the results and should be investigated in further studies. More contemporary activities, such as playing video games, may influence sleep in certain groups (30). Likewise, work times may be an important factor, as suggested by the occupation-related differences in insomnia (5). Rise time was significantly earlier in the occupational groups with shorter sleep duration, both for shift and day workers, while the effect of occupational group on bedtimes was more ambiguous. Circadian factors may play a role; having a preference for mornings may be the reason why individuals choose occupations with early start times, while being an evening person may contribute to sleep loss (31). In our study, however, there were no systematic differences in "morningness" versus "eveningness" that could explain the occupation-related differences in sleep duration. Rise time is related to when work starts in the morning and also to shift schedules. In a small study on an airline cabin crew, early morning work reduced sleep and increased daytime sleepiness (32). Also, train drivers on early morning shifts slept $1-2$ hours less than train drivers on day or evening shifts, and had increased sleepiness on the job as a result (33). However, in our study, rise time in the occupational groups with shorter sleep duration was earlier also for day workers. There were very small differences in subjective sleep need between the occupations. Thus it seems that the behavioral factor of getting up in the morning, but not going to bed early enough to compensate for the early rise time, is an important determinant of the shorter sleep duration in some occupations for both shift workers and day workers. For the craft and construction workers, plant and machine operators, and drivers, the conflict between the work-related early rise times and evening social functioning may be worse than for the other occupational groups studied here. One may ask whether the early rise times and related work and shift start times are really necessary for all the effected occupations. 
In the questionnaire employed in this study, no distinctions were made between shift work, night work or watches, nor were there any questions on shift schedules, timing or rotation. This was beyond our control, and may have biased the results, probably by under-reporting the effect of shift work on the parameters studied. Our research confirmed findings from other studies $(3,4$, 34) that shift workers sleep less than day workers, even though there was no distinction between shift work and watches. This is in line with the finding that sleep may be disturbed in on-call situations, even when the subjects are not awakened (35). There was also a greater tendency for very short sleep ( $<6$ hours) in the shift workers in the present material. Sleepiness is commonly reported in shift workers (2-4), and may be dependent on the shift rotation (36). The subjects undertaking shift work or watches in our study did not report more daytime sleepiness than day workers. This may have been an effect of the unqualified form of the shift work question. However, another reason for the low report on sleepiness may be the fact that our study population was limited to the age group of $40-45$ years. Compared to day workers, in our study, shift workers reported more unintentional sleep (falling asleep at work). In a large Swedish study, the prevalence of unintentional sleep was 7\% during work hours, with a reduced risk for subjects under 45 years, and an increased risk with shift work and higher socioeconomic status (37). This is consistent with our findings for 40-45 year olds of an overall prevalence of $5.5 \%$, increasing to $7.4 \%$ for shift workers. Also, the shift workers in our study reported more insomnia than day workers, as noted before $(3,38)$. Current, but also past shift work may lead to problems falling asleep and early awakenings (38). Insomnia in shift workers depends on the shift system, in addition to lifestyle factors and age (3). In our study, all subjects were 40 to 45 years old; we adjusted for lifestyle factors like exercise, smoking, and alcohol consumption. Still there was a clearly increased risk of insomnia in the shift workers. The reduced sleep duration and increased tendency to fall asleep at work demonstrated in shift workers may be a consequence of the tendency towards insomnia. Shift workers may also face problems adjusting to the circadian system (39).

In our study, occupation and shift work have similar effects on sleep duration and rise time during the working week. As shown in table 2, shift work and occupation seem to have additive effects on sleep duration. The difference between sleep duration in shift workers and day workers was significant in three of the occupational groups and showed a tendency towards significance in two other occupational groups. The material, particularly on shift workers, is not large enough to conclude definitively that occupation and shift work have additive effects on sleep duration. In any case, it is clear from the result in the day workers that the effects of occupational group on sleep duration are independent of the effects of shift work. It remains an open question whether the effects of shift work on sleep are independent of the type of occupation.

This was a large, population-based study. The initial participation rate of $63 \%$ may seem low but is not unusual for such epidemiological studies. A low participation rate may not influence the associations studied but may make the prevalence data, in particular, less reliable. Another limitation of the study was that the sleep data were subjective and reported from memory on a single occasion, in a traditional point estimate (40). The quality of the data may therefore have varied with the question asked. However, in a study of self-reported sleep measures, quantitative estimates of usual sleep behavior were found to be highly reliable (40). Sleep duration was calculated from self-reported habitual bed- and rise time, subtracting self-reported sleep latency (10). In our opinion, this gives a more reliable measure of sleep duration than simply asking subjects to report sleep duration.

The population study was limited to $40-45$ year olds. Age influences an individual's ability to adjust to repeated night shifts (41). Also, it is well known that sleep varies with age (42). However, the mean sleep duration in our study was similar to that of several other studies comprising wider age groups (10). The limited age group of this study may also be considered an advantage, making the data more homogeneous. The subjects had been, in general, rather stable in their occupation, and ought to be representative of their occupational groups.

In conclusion, our data indicated that occupation as well as shift work have effects sleep duration and sleeprelated problems, and that the effects of occupation are independent of those of shift work.

\section{References}

1. Åkerstedt T. Shift work and disturbed sleep/wakefulness. Sleep Med Rev. 1998;2:117-28.

2. Åkerstedt T, Torsvall L, Gillberg M. Sleepiness in shift work: a review with emphasis on continuous monitoring of EEG and EOG. Chronobiol Int. 1987;4:129-40.

3. Härmä M, Tenkanen L, Sjöblom T, Alikoski T, Heinsalmi P. Combined effects of shift work and life-style on the prevalence of insomnia, sleep deprivation and daytime sleepiness. Scand J Work Environ Health. 1998;24(4):300-7.

4. Drake CL, Roehrs T, Richardson G, Walsh JK, Roth T. Shift work sleep disorder: prevalence and consequences beyond that of symptomatic day workers. Sleep. 2004;27:1453-62.

5. Partinen M, Eskelinen L, Tuomi K. Complaints of insomnia in different occupations. Scand J Work Environ Health. 1984;10:467-69. 
6. Kronholm E, Härmä M, Hublin C, Aro AR, Partonen T. Selfreported sleep duration in Finnish general population. J Sleep Res. 2006;15:276-90

7. Gottlieb DJ, Punjabi NM, Newman AB, Resnick HE, Redline $\mathrm{S}$, Baldwin CM, et al. Association of sleep time with diabetes mellitus and impaired glucose tolerance. Arch Intern Med. 2005;165:863-67.

8. Gottlieb DJ, Redline S, Nieto FJ, Baldwin CM, Newman AB, Resnick HE, et al. Association of usual sleep duration with hypertension: the Sleep Heart Health Study. Sleep. 2006;29:1009-14.

9. Cavelaars AE, Kunst AE, Geurts JJ, Helmert U, Lundberg O, Mielck A, et al. Morbidity differences by occupational class among men in seven European countries: an application of the Erikson - Goldthorpe social class scheme. Int J Epidemiol. 1998;27:222-30.

10. Ursin R, Bjorvatn B, Holsten F. Sleep duration, subjective sleep need, and sleep habits of 40- to 45-year-olds in the Hordaland Health Study. Sleep. 2005;28:1260-9.

11. Statistics Norway. Statistisk årbok [Statistical year book][Internet]. Oslo: Statistics Norway; 2004 [cited 28 April 2009]. Available online: http://www.ssb.no/english/yearbook/2004/

12. International Labour Organization. International Standard Classification of Occupations (ISCO-88). Geneva: ILO; 1988.

13. Riise T, Moen BE, Nortvedt MW. Occupation, lifestyle factors and health-related quality of life: the Hordaland Health Study. J Occup Environ Med. 2003;45:324-32.

14. Kecklund G, Akerstedt T. The psychometric properties of the Karolinska Sleep Questionnaire. J Sleep Res. 1992;1 suppl 1:113.

15. Ihlebæk C, Eriksen HR. Occupational and social variation in subjective health complaints. Occup Med. 2003;53:270-8.

16. Mitler MM, Miller JC, Lipsitz JJ, Walsh JK, Wylie CD. The sleep of long-haul truck drivers. N Engl J Med. 1997;337:755-61.

17. Hanowski RJ, Wierwille WW, Dingus TA. An on-road study to investigate fatigue in local/short haul trucking. Accid Anal Prev. 2003;35:153-60.

18. Hanowski RJ, Hickman J, Fumero MC, Olson RL, Dingus TA. The sleep of commercial vehicle drivers under the 2003 hoursof-service regulations. Accid Anal Prev. 2007;39:1140-5.

19. Kripke DF, Garfinkel L, Wingard DL, Klauber MR, Marler MR. Mortality associated with sleep duration and insomnia. Arch Gen Psychiatry. 2002;59:131-6.

20. Jewett ME, Dijk DJ, Kronauer RE, Dinges DF. Dose-response relationship between sleep duration and human psychomotor vigilance and subjective alertness. Sleep. 1999;22:171-9.

21. Philip P, Ghorayeb I, Stoohs R, Menny JC, Dabadie P, Bioulac $\mathrm{B}$, et al. Determinants of sleepiness in automobile drivers. J Psychosom Res. 1996;41:279_88.

22. Hublin C, Kaprio J, Partinen M, Koskenvuo M. Insufficient sleep - a population based study in adults. Sleep. 2001;24:392-400.

23. Spiegel K, Knutson K, Leproult R, Tasali E, Van Cauter E. Sleep loss: a novel risk factor for insulin resistance and type 2 diabetes. J Appl Physiol. 2005;99: 2008-19.

24. Gangwisch JE, Malaspina D, Boden-Albala B, Heymsfield SB. Inadequate sleep as a risk factor for obesity: analyses of the NHANES I. Sleep. 2005;28:1289-96.
25. Bjorvatn B, Sagen IM, Øyane N, Waage S, Fetveit A, Pallesen S, et al. The association between sleep duration, body mass index and metabolic measures in the Hordaland Health Study. J Sleep Res. 2007;16:66-76.

26. Li X, Sundquist K, Sundquist J. Socioeconomic status and occupation as risk factors for obstructive sleep apnea in Sweden: a population-based study. Sleep Med. 2008;9:129-36.

27. Åkerstedt T. Pscychosocial stress and impaired sleep [review]. Scand J Work Environ Health. 2006;32(6, special issue):493-501.

28. Fahlén G, Knutsson A, Peter R, Åkerstedt T, Nordin M, Alfredsson L, et al. Effort-reward imbalance, sleep disturbances and fatigue. Int Arch Occup Environ Health. 2006;79:371-8.

29. Miranda H, Viikari-Juntura E, Punnett L, Riihimäki H. Occupational loading, health behavior and sleep disturbance as predictors of low-back pain. Scand J Work Environ Health. 2008;34(6):411-19.

30. Smyth JM. Beyond self-selection in video game play: an experimental examination of the consequences of massively multiplayer online role-playing game play. Cyberpsychol Behav. 2007;10:717-21.

31. Van Dongen HP. Shift work and inter-individual differences in sleep and sleepiness. Chronobiol Int. 2006;23:1139-47.

32. Kecklund G, Akerstedt T, Lowden A. Morning work: effects of early rising on sleep and alertness. Sleep. 1997;20:215-23.

33. Ingre M, Kecklund G, Akerstedt T, Kecklund L. Variation in sleepiness during early morning shifts: a mixed model approach to an experimental field study of train drivers. Chronobiol Int. 2004;21:973-90

34. Axelsson J, Åkerstedt T, Kecklund G, Lowden A. Tolerance to shift work - how does it relate to sleep and wakefulness? Int Arch Occup Environ Health. 2004;77:121-9.

35. Torsvall L, Åkerstedt T. Disturbed sleep while being on call: an EEG study of ships' engineers. Sleep. 1988;11:35-38.

36. Viitasalo K, Kuosma E, Laitinen J, Härmä M. Effects of shift rotation and the flexibility of a shift system on daytime alertness and cardiovascular risk factors. Scand J Work Environ Health. 2008;34(3):198-205.

37. Åkerstedt T, Knutsson A, Westerholm P, Theorell T, Alfredsson L, Kecklund G. Work organisation and unintentional sleep: results from the WOLF study. Occup Environ Med. 2002;59:595-600.

38. Marquié JC, Foret J. Sleep, age, and shift work experience. J Sleep Res. 1999;8:297-304.

39. Åkerstedt T. Psychological and psychophysiological effects of shift work. Scand J Work Environ Health. 1990;16 suppl 1:67-73.

40. Gehrman P, Matt GE, Turingan M, Dinh Q, Ancoli-Israel S. Towards an understanding of self-reports of sleep. J Sleep Res. 2002;11:229-36.

41. Härmä MI, Hakola T, Akerstedt T, Laitinen JT. Age and adjustment to night work. Occup Environ Med. 1994;51:568-73.

42. Bliwise DL. Sleep in normal aging and dementia. Sleep. 1993;16:40-81.

Received for publication: 30 September 2008 